\title{
Effect of the Early Introduction of Mild Mobilization Performed by Nurses on the Recovery of Patients in the Intensive Care Unit
}

\author{
Yuta Mitobe', Yu Koyama², Hagiko Aoki², Utako Shimizu², Yoshiyuki Muramatsu², \\ Chikayo Koyama², Sayuri Sakai², Yuka Iwasa², Jun Kikunaga², Megumi Taguchi², \\ Masakazu Nitta ${ }^{3}$, Hiroshi Endoh ${ }^{3}$, Masaki Kitajima1, Shinichiro Morishita ${ }^{4}$ \\ ${ }^{1}$ Niigata University of Health and Welfare, Niigata, Japan \\ ${ }^{2}$ Department of Nursing, Niigata University Graduate School of Health Sciences, Niigata, Japan \\ ${ }^{3}$ Division of Emergency, Critical Care Medicine, Niigata University Graduate School of Medical, Niigata, Japan \\ ${ }^{4}$ Institute for Human Movement and Medical Sciences, Niigata University of Health and Welfare, Niigata, Japan \\ Email: mitobe@nuhw.ac.jp
}

How to cite this paper: Mitobe, Y., Koyama, Y., Aoki, H., Shimizu, U., Muramatsu, Y., Koyama, C., Sakai, S., Iwasa, Y., Kikunaga, J., Taguchi, M., Nitta, M., Endoh, H., Kitajima, M. and Morishita, S. (2016) Effect of the Early Introduction of Mild Mobilization Performed by Nurses on the Recovery of Patients in the Intensive Care Unit. Open Journal of Nursing, 6, 969-976. http://dx.doi.org/10.4236/ojn.2016.612093

Received: October 16, 2016

Accepted: November 28, 2016

Published: December 1, 2016

Copyright (c) 2016 by authors and Scientific Research Publishing Inc. This work is licensed under the Creative Commons Attribution International License (CC BY 4.0).

http://creativecommons.org/licenses/by/4.0/ (c) (i) Open Access

\begin{abstract}
Rationale: Recent studies have reported the effectiveness of the early introduction of rehabilitation for preventing muscle weakness in patients in the intensive care unit (ICU). The early introduction of full-scale rehabilitation by a physical therapist is difficult in some cases because of disease severity and/or patient conditions. However, mild mobilization by a nurse (MMN), as a part of standard care performed, may have a positive effect on patient recovery. We examined the effect of the early introduction of MMN on the recovery of patients in the ICU. Methods: We retrospectively examined patients admitted to Niigata University Hospital's ICU during between April 2014 and March 2015 who were receiving mechanical ventilation for 7 days or more. Patients were divided into two groups according to the date of initiation of MMN: group L comprised patients for whom MMN was started after 72 hours and group E comprised patients for whom MMN was started within 72 hours after ICU admission. The data were analyzed using the Fisher test, Mann-Whitney $\mathrm{U}$ test, and Wilcoxon test. Statistical significance was defined as $P<0.05$. Results: Sixty-three patients were included: 42 patients in group L and 21 in group $E$. There was no significant difference between the two groups in patients' background, including the type of illness, steroid use, presence of sepsis or diabetes, and sequential organ failure assessment (SOFA) score on ICU admission; however, the SOFA score at ICU discharge was significantly decreased in group E compared to that in group L (6.21 versus $4.30 ; P=0.034)$. Conclusion: Our results indicate that MMN may reduce disease severity if started within 72 hours after ICU admission.
\end{abstract}




\section{Keywords}

Intensive Care Unit (ICU), Nurse, Mobilization,

Sequential Organ Failure Assessment (SOFA) Score

\section{Introduction}

Recent studies have demonstrated that supportive care can increase the survival rate of critically ill patients [1] [2] [3]. Patients in the intensive care unit (ICU) can rally from critical illness; subsequently, they return to daily life. Critically ill patients have a lower quality of life (QOL) because of a functional disorder of their body or mind [4] [5] [6]. Therefore, patients in the ICU after hospital discharge may have a worse QOL [4] [5]. In a previous study, improvement in the disease severity has not been shown as an effect of earlier ambulation on patients on artificial breathing [7]. The efficacy of early mobilization has been reported, and the effects of early mobilization on patients on artificial breathing include the following: improved functional independence, reduced ICU delirium, reduced duration of mechanical ventilation, reduced ICU length of stay, reduced hospital length of stay, improved 6-minute walk distance, improved QOL, and improved muscle strength. Recent studies have demonstrated that early mobility in the ICU is safe and feasible, with a potential reduction in short-term physical impairment by the intervention of a physical therapist. However, the effectiveness of early mobilization with an ICU nurse has not been reported until now [8] [9] [10]. Although a nurse is included in the early ambulation team, only the effect of intervention by a team has been shown [11] [12]. Therefore, the present study aimed to evaluate the effectiveness of enforcing early mobilization and nursing care for patients admitted in the ICU.

\section{Method}

\subsection{Patients Selection}

We retrospectively examined patients admitted to Niigata University Hospital's ICU between April 2014 and March 2015.Inclusion criteria were receiving mechanical ventilation for 7 days or more, and patients aged $\geq 20$ years and $\leq 75$ years who were diagnosed as having sepsis, pneumonia, acute respiration failure, or exacerbation of chronic respiratory failure were included in the present study. Exclusion criteria were as follows: patients aged $\geq 75$ years or $\leq 20$ years, those for whom the ICU nurse did not perform mobilization, and patients hospitalized more than twice in the ICU.

We defined mild mobilization by a nurse (MMN) when an ICU nurse performs an active range of motion or passive range of motion, passive sitting position, and breathing exercise more than once to a patient since ICU admission.

Ninety patients were selected for analysis. This study was approved by the research ethics committee of Niigata University Graduate School of Health Sciences (approval no.: 124). The histogram of the start of the intervention for MMN showed a bimodal distribution over 4 days (Figure 1). Patients were divided into two groups by the date 


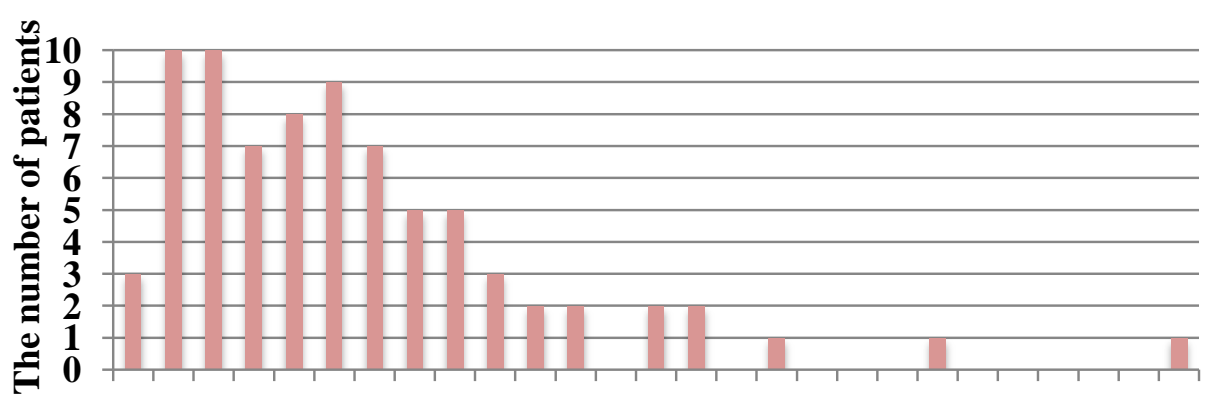

\section{7 Start of intervention day}

Figure 1. The start day of mild mobilization of a nurse. Mean \pm SD: $6.47 \pm 4.69$ days Median: 6 days.

of initiation of MMN: group L comprised patients with MMN starting after 72 hours, and group E comprised patients with MMN starting within a 72-hour period after ICU admission. We extracted data on patients' background (sex, basic disorder, and the presence of diabetes mellitus) from their medical charts. We also extracted the following clinical data on ICU admission from patients' medical charts: age, height, weight, body mass index (BMI), sequential organ failure assessment (SOFA) score, albumin level, blood urea nitrogen (BUN) level, creatinine (Cr) level, C-reactive protein (CRP) level, glucose level, glutamic oxaloacetic transaminase (GOT) level, glutamic pyruvic transaminase (GPT) level, total bilirubin level, and white blood cell (WBC) count. In addition, we extracted the following data on the features of nursing care during ICU admission from the medical charts: change in the body position, bed leaving, rehabilitation, and bed bath. Lastly, we extracted the following data on patients' clinical features on ICU discharge from the medical charts: age, height, weight, BMI, SOFA score, albumin level, BUN level, Cr level, CRP level, glucose level, GOT level, GPT level, total bilirubin level, WBC count, Glasgow Coma Scale (GCS) score, and ventilator days. There were no missing physiological data or data outliers.

\subsection{Statistical Analysis}

Data were analyzed using the Fisher test and Mann-Whitney U test. Statistical significance was defined as $P<0.05$. All statistical analyses were performed using EZR (Saitama Medical Center, Jichi Medical University, Saitama, Japan), which is a graphical user interface for R (The R Foundation for Statistical Computing, Vienna, Austria). More precisely, it is a modified version of $\mathrm{R}$ commander designed to add statistical functions frequently used in biostatistics.

\section{Results}

\subsection{Clinical Features and Background of the Patients}

Of 63 enrolled patients, 42 were classified into group L, and 21 were classified into group E. Group L and group E were comparable in sex, basic disorder and the presence of diabetes mellitus (Table 1). 
Table 1. Clinical features and background of patients.

\begin{tabular}{cccc}
\hline & Group $L, n=42$ & Group $E, n=21$ & $P$-value \\
\hline Average age (years) & $58.77 \pm 13.25$ & $58.00 \pm 13.52$ & 0.478 \\
Sex (\%) & & & \\
Female & $19(67.8)$ & $9(32.2)$ & \\
Male & $23(65.7)$ & $12(34.3)$ & \\
Basic disorder (\%) & & & \\
Pneumonia (lung disorder) & $22(61.1)$ & $14(38.9)$ & \\
Sepsis (serious bacterial disease) & $13(86.6)$ & $2(13.4)$ & \\
Atherosclerosis (heart disease) & $7(58.3)$ & $5(41.7)$ & \\
Diabetes mellitus (\%) & & $13(34.3)$ & \\
Negative & $25(65.7)$ & $8(32.0)$ & \\
Positive & $17(68.0)$ & & \\
\hline
\end{tabular}

\subsection{Clinical Features on ICU Admission}

The BUN level was significantly lower in group L than in group E $(39.97 \mathrm{mg} / \mathrm{dL}$ vs. $31.57 \mathrm{mg} / \mathrm{dL}, P=0.041)$. All clinical data, except the BUN level, were not significantly different between groups $\mathrm{L}$ and $\mathrm{E}$ (Table 2).

\subsection{Clinical Features at ICU Discharge}

Group L and group E were comparable in frequency of changing the patients' body position, bed leaving, rehabilitation, and clean care (Table 3). We evaluated the effects of the features of nursing care, and we found that nursing care was performed the same way in both groups.

\subsection{Features of Nursing Care during ICU Discharge}

The SOFA score at discharge was significantly lower in group E than in group L (6.21 versus $4.30 ; P=0.034)$. All nursing care data, except the SOFA score at discharge, was not significantly different between groups $\mathrm{L}$ and $\mathrm{E}$. There was no significant difference in the ventilator days between the two groups (group L: 9.47 versus group E: $8.50 ; P=$ 0.344). Although not significant, the GCS score improved more in patients in group E than in those in group L (13.80 versus 11.86; $P=0.113$ ) (Table 4).

\section{Discussion}

First, we will discuss the characteristics of nursing care during ICU admission. In general, changing the patient's body position prevents pressure sores, reduces pain due to bed rest, and facilitates postural drainage [13]. The complications reportedly associated with bed rest among patients in the ICU are as follows: pneumonia, atelectasis, orthostatic hypotension, atrophy of the muscles, pressure sores, and psychological stress [14] [15] [16] [17] [18]. Recent studies have demonstrated that early mobilization is effective 
Table 2. Clinical features on ICU admission.

\begin{tabular}{cccc}
\hline & \multicolumn{2}{c}{ Mean \pm SD } & \multirow{2}{*}{ P-value } \\
\cline { 2 - 3 } & Group $L, \boldsymbol{n}=\mathbf{4 2}$ & Group $E, \boldsymbol{n}=\mathbf{2 1}$ & 0.661 \\
Height $(\mathrm{cm})$ & $160.25 \pm 9.89$ & $163.10 \pm 9.42$ & 0.584 \\
Weight $(\mathrm{kg})$ & $57.73 \pm 14.13$ & $55.96 \pm 15.91$ & 0.53 \\
BMI $\left(\mathrm{kg} / \mathrm{m}^{2}\right)$ & $21.86 \pm 5.47$ & $20.84 \pm 4.26$ & 0.29 \\
SOFA score at admission & $10.10 \pm 4.47$ & $8.54 \pm 4.06$ & 0.118 \\
Albumin level $(\mathrm{g} / \mathrm{dL})$ & $2.41 \pm 0.74$ & $2.75 \pm 0.88$ & 0.041 \\
BUN level $(\mathrm{mg} / \mathrm{dL})$ & $39.97 \pm 28.63$ & $31.57 \pm 32.02$ & 0.41 \\
Cr level $(\mathrm{mg} / \mathrm{dL})$ & $1.5 \pm 1.34$ & $1.28 \pm 1.30$ & 0.054 \\
CRP level $(\mathrm{mg} / \mathrm{L})$ & $17.83 \pm 13.95$ & $10.59 \pm 9.33$ & 0.726 \\
Glucose level $(\mathrm{mg} / \mathrm{dL})$ & $170.78 \pm 71.03$ & $161.47 \pm 63.74$ & 0.243 \\
AST level $(\mathrm{IU} / \mathrm{L})$ & $151.64 \pm 251.41$ & $94.90 \pm 178.27$ & 0.089 \\
ALT level $(\mathrm{IU} / \mathrm{L})$ & $124.38 \pm 256.42$ & $59.00 \pm 84.19$ & 0.305 \\
T.bil level $(\mathrm{mg} / \mathrm{dL})$ & $3.08 \pm 5.27$ & $1.49 \pm 1.77$ & 0.293 \\
WBC count $\left(10^{3} / \mu \mathrm{L}\right)$ & $10,204.76 \pm 9041.48$ & $11,057.62 \pm 5928.44$ & \\
\hline
\end{tabular}

SD: Standard Deviation; BUN: Blood Urea Nitrogen; Cr: Creatinine; CRP: C-Reactive Protein; GOT: Glutamic Oxaloacetic Transaminase; GPT: Glutamic Pyruvic Transaminase; T. bil: Total bilirubin; WBC: White Blood Cell.

Table 3. Features of nursing care during ICU admission.

\begin{tabular}{cccc}
\hline & \multicolumn{2}{c}{ Mean \pm SD } & \multirow{2}{*}{ P-value } \\
\cline { 2 - 3 } & Group $\mathbf{L}, \boldsymbol{n}=\mathbf{4 2}$ & Group $\boldsymbol{E}, \boldsymbol{n}=\mathbf{2 1}$ & 0.163 \\
Changing body position & $9.77 \pm 4.84$ & $8.27 \pm 5.84$ & 0.139 \\
Bed leaving & $1.34 \pm 0.68$ & $1.12 \pm 0.79$ & 0.683 \\
Rehabilitation & $0.08 \pm 0.25$ & $0.103 \pm 0.162$ & 0.342 \\
Bed bath & $1.23 \pm 0.74$ & $1.36 \pm 1.61$ & \\
\hline
\end{tabular}

SD, standard deviation.

Table 4. Clinical features at ICU discharge.

\begin{tabular}{cccc}
\hline & \multicolumn{2}{c}{ Mean \pm SD } & P-value \\
\cline { 2 - 3 } & Group $L, \boldsymbol{n}=\mathbf{4 2}$ & Group $\boldsymbol{E}, \boldsymbol{n}=\mathbf{2 1}$ & 0.486 \\
ICU stay (day) & $17.76 \pm 12.19$ & $15.80 \pm 9.98$ & $0.034^{*}$ \\
SOFA score at discharge & $6.21 \pm 3.40$ & $4.30 \pm 2.79$ & 0.731 \\
Alb level (g/dL) & $2.51 \pm 0.69$ & $2.57 \pm 0.66$ & 0.226 \\
BUN level (mg/dL) & $35.69 \pm 34.02$ & $31.1 \pm 32.29$ & 0.569 \\
Cr level (mg/dL) & $1.20 \pm 1.91$ & $0.85 \pm 0.86$ & 0.804 \\
CRP level (mg/L) & $4.33 \pm 4.07$ & $4.69 \pm 5.01$ & 0.117 \\
Glucose level (mg/dL) & $135.59 \pm 39.15$ & $123.80 \pm 40.07$ & 0.448 \\
GOT level (IU/L) & $76.33 \pm 126.04$ & $36.80 \pm 15.62$ & 0.089 \\
GPT level (IU/L) & $120.02 \pm 330.72$ & $43.33 \pm 24.73$ & 0.05 \\
T.bil level (mg/dL) & $3.08 \pm 5.27$ & $1.49 \pm 1.77$ & 0.073 \\
WBC count (K/mcL) & $10,213.33 \pm 5122.60$ & $7818.57 \pm 2611.78$ & 0.113 \\
GCS score & $11.86 \pm 3.77$ & $13.80 \pm 1.63$ & 0.344 \\
Ventilator days & $9.47 \pm 3.77$ & $8.50 \pm 6.92$ & \\
\hline
\end{tabular}

BUN: Blood Urea Nitrogen; Cr: Creatinine; CRP: C-Reactive Protein; GOT: Glutamic Oxaloacetic Transaminase; GPT: Glutamic Pyruvic Transaminase; T. bil: Total bilirubin; WBC: White Blood Cell; GCS: Glasgow Coma Scale. 
in patients in the ICU for preventing complications due to bed rest. Consequently, the first recommended intervention of early mobilization is changing the body position every 2 hours [11] [18]. The mobility protocol by Morris et al. proposed that patients in the ICU should be turned and repositioned every 2 hours [11]. However, in our study, the body position was changed every 3 hours. The SOFA score at discharge was significantly lower in group $\mathrm{E}$ than in group $\mathrm{L}(P=0.034)$. Thus, our study's findings suggest that changing the body position every 3 hours is sufficiently effective.

The second point we will discuss is the relationship between MMN and the SOFA score. Our results showed no significant difference in the clinical features and background of patients in both groups. Thus, the clinical features and background of patients were comparable between group L and group E. In our study, the SOFA score was used to evaluate the disease severity of patients in the ICU. The SOFA score is composed of scores from six organ systems, graded from 0 (normal) to 4 (the most abnormal) according to the degree of dysfunction/failure, with a daily score of $0-24$ points [19]. The results indicate that there was no significant difference in the SOFA score at admission. However, there was a significant difference in the SOFA score at discharge (Figure 2). Previous studies have shown mixed results regarding reduced mechanical ventilation and an improved level of consciousness as an effect of early mobilization in patients in the ICU [20]. The mean ventilator days were shorter in group E than in group L, and the mean GCS score at discharge improved more in group E than in group L; however, these findings were insignificant. Improvement in the SOFA score may be affected by shorter ventilation days and/or an improved GCS score by MMN.

\section{Limitations}

Several limitations of this study should be acknowledged. An inherent limitation of our study is that it was a retrospective chart review. Therefore, we cannot rule out the possibility of selection and survivor bias. Patients in both groups were recruited at different
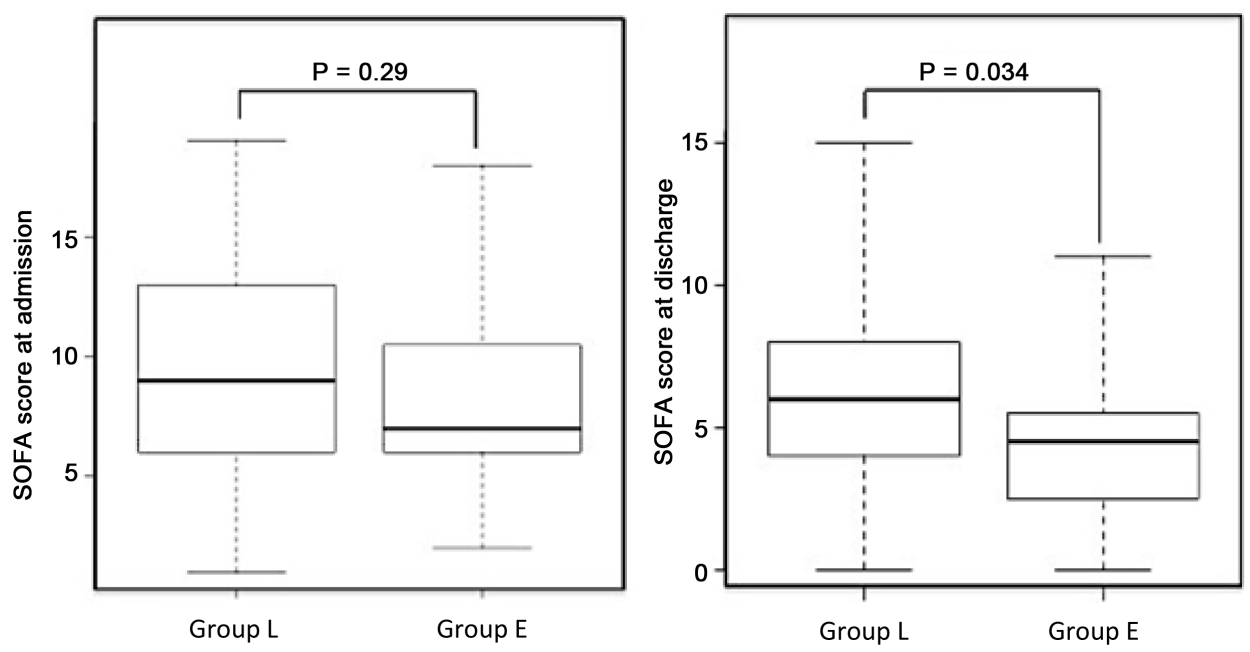

Figure 2. There was no significant difference between the groups in the SOFA score at admission. The SOFA score at discharge was significantly lower in Group E compared with Group L. 
time points, and the decision to perform MMN was not randomized. Additionally, missing data precluded some patients from being included in the analysis. Accordingly, a prospective study will be necessary to elucidate the advantage of early mobilization by an ICU nurse, and we hope our present study's findings provide a cornerstone for such clinical research.

\section{Conclusion}

Our study's results indicate that MMN may reduce disease severity if started within 72 hours after ICU admission.

\section{Acknowledgements}

We acknowledge the nursing staff and medical doctors of the Department of Emergency \& Critical Medicine, Niigata University of Medicine for their support in this study.

\section{Conflicts of Interest}

The authors declare no conflicts of interest.

\section{References}

[1] Rubenfeld, G.D., Caldwell, E., Peabody, E., Weaver, J., Martin, D.P., Neff, M., Stern, E.J. and Hudson, L.D. (2005) Incidence and Outcomes of Acute Lung Injury. The New England Journal of Medicine, 16, 1685-1693. https://doi.org/10.1056/NEJMoa050333

[2] Bersten, A.D., Edibam, C., Hunt, T., Moran, J. and Australian and New Zealand Intensive Care Society Clinical Trials Group (2002) Incidence and Mortality of Acute Lung Injury and the Acute Respiratory Distress Syndrome in Three Australian States. American Journal of Respiratory and Critical Care Medicine, 15, 443-448. https://doi.org/10.1097/00003246-198704000-00208

[3] Milberg, J.A., Davis, D.R., Steinberg, K.P. and Hudson, L.D. (1995) Improved Survival of Patients with Acute Respiratory Distress Syndrome (ARDS): 1983-1993. The Latest Medical Research, 25, 306-309. https://doi.org/10.1097/00132586-199510000-00011

[4] Mikkelsen, M.E., Shull, W.H., Biester, R.C., Taichman, D.B., Lynch, S., Demissie, E., Hansen-Flaschen, J. and Christie, J.D. (2009) Cognitive, Mood and Quality of Life Impairments in a Select Population of ARDS Survivors. Respirology, 14, 76-82.

https://doi.org/10.1111/j.1440-1843.2008.01419.x

[5] Hopkins, R.O., Weaver, L.K., Collingridge, D., Parkinson, R.B., Chan, K.J. and Orme Jr., J.F. (2005) Two-Year Cognitive, Emotional, and Quality-Of-Life Outcomes in Acute Respiratory Distress Syndrome. American Journal of Respiratory and Critical Care Medicine, 171, 340-347. https://doi.org/10.1164/rccm.200406-763OC

[6] Oeyen, S.G., Vandijck, D.M., Benoit, D.D., Annemans, L. and Decruyenaere, J.M. (2010) Quality of Life after Intensive Care: A Systematic Review of the Literature. Critical Care Medicine, 38, 2386-2400. https://doi.org/10.1097/CCM.0b013e3181f3dec5

[7] Schweickert, W.D. and Kress, J.P. (2011) Implementing Early Mobilization Interventions in Mechanically Ventilated Patients in the ICU. Chest, 140, 1612-1617. https://doi.org/10.1378/chest.10-2829

[8] Bailey, P., Thomsen, G.E. and Spuhler, V.J. (2007) Early Activity Is Feasible and Safe in Respiratory Failure Patients. Critical Care Medicine, 35, 139-145. 


\section{https://doi.org/10.1097/01.CCM.0000251130.69568.87}

[9] Schweickert, W.D., Pohlman, M.C. and Pohlman, A.S. (2009) Early Physical and Occupational Therapy in Mechanically Ventilated, Critically Ill Patients: A Randomised Controlled trial. Lancet, 373, 1874-1882. https://doi.org/10.1016/S0140-6736(09)60658-9

[10] Burtin, C., Clerckx, B. and Robbeets, C. (2009) Early Exercise in Critically Ill Patients Enhances Short-Term Functional Recovery. Critical Care Medicine, 37, 2499-2505. https://doi.org/10.1097/CCM.0b013e3181a38937

[11] Morris, P.E., Goad, A., Thompson, C., Taylor, K., Harry, B., Passmore, L., Ross, A., Anderson, L., Baker, S., Sanchez, M., Penley, L., Howard, A., Dixon, L., Leach, S., Small, R., Hite, R.D. and Haponik, E. (2008) Early Intensive Care Unit Mobility Therapy in the Treatment of Acute Respiratory Failure. Critical Care Medicine, 36, 2238-2243.

https://doi.org/10.1097/CCM.0b013e318180b90e

[12] Dammeyer, J.A., Baldwin, N., Packard, D., Harrington, S., Christofferson, B., Christopher, J., Strachan, C.L. and Iwashyna, J. (2013) Mobilizing Outcomes: Implementation of a Nurse-Led Multidisciplinary Mobility Program. Critical Care Nurse Q, 36, 109-119. https://doi.org/10.1097/CNQ.0b013e31827535db

[13] Davis Jr, K., Johannigman, J.A., Campbell, R.S., Marraccini, A., Luchette, F.A., Frame, S.B. and Branson, R.D. (2001) The Acute Effects of Body Position Strategies and Respiratory Therapy in Paralyzed Patients with Acute Lung Injury. Critical Care, 5, 81-87. https://doi.org/10.1186/cc991

[14] Greenleaf, J.E. and Kozlowski, S. (1982) Physiological Consequences of Reduced Physical Activity during Bed Rest. Exercise and Sport Sciences Reviews, 10, 84-119.

https://doi.org/10.1249/00003677-198201000-00004

[15] Allen, C., Glasziou, P. and Del Mar, C. (1999) Bed Rest: A Potentially Harmful Treatment Needing More Careful Evaluation. Lancet, 354, 1229-1233. https://doi.org/10.1016/S0140-6736(98)10063-6

[16] Pavy-Le Traon, A., Heer, M., Narici, M.V., Rittweger, J. and Vernikos, J. (2007) From Space to Earth: Advances in Human Physiology from 20 Years of Bed Rest Studies (1986-2006). European Journal of Applied Physiology, 101, 143-194. https://doi.org/10.1007/s00421-007-0474-Z

[17] van der Schaaf, M., Beelen, A., Dongelmans, D.A., Vroom, M.B. and Nollet. F. (2009) Poor Functional Recovery after a Critical Illness: A Longitudinal Study. Journal of Rehabilitation Medicine, 41, 1041-1048. https://doi.org/10.2340/16501977-0443

[18] Vollman, K.M. (2010) Introduction to Progressive Mobility. Critical Care Nurse, 30, S3-S5. https://doi.org/10.4037/ccn2010803

[19] Pätilä, T., Kukkonen, S., Vento, A., Pettilä, V. and Suojaranta-Ylinen, R. (2006) Relation of the Sequential Organ Failure Assessment Score to Morbidity and Mortality after Cardiac Surgery. The Annals of Thoracic Surgery, 82, 2072-2078.

https://doi.org/10.1016/j.athoracsur.2006.06.025

[20] Schweickert, W.D., Pohlman, M.C., Pohlman, A.S., Nigos, C., Pawlik, A.J., Esbrook, C.L., Spears, L., Miller, M., Franczyk, M., Deprizio, D., Schmidt, G.A., Bowman, A., Barr, R., McCallister, K.E., Hall, J.B. and Kress, J.P. (2009) Early Physical and Occupational Therapy in Mechanically Ventilated, Critically Ill Patients: A Randomised Controlled Trial. Lancet, 30, 1874-1882. https://doi.org/10.1016/S0140-6736(09)60658-9 
Submit or recommend next manuscript to SCIRP and we will provide best service for you:

Accepting pre-submission inquiries through Email, Facebook, LinkedIn, Twitter, etc.

A wide selection of journals (inclusive of 9 subjects, more than 200 journals)

Providing 24-hour high-quality service

User-friendly online submission system

Fair and swift peer-review system

Efficient typesetting and proofreading procedure

Display of the result of downloads and visits, as well as the number of cited articles

Maximum dissemination of your research work

Submit your manuscript at: http://papersubmission.scirp.org/

Or contact ojn@scirp.org 